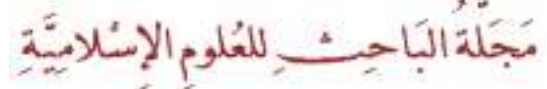

Researcher Journal For Islamic Sciences

Published by the College of Islamic Sciences at the University of Fallujah

ISSN p.p:2708-3993 / ISSN 0.l: 2708-4000

Vol;1- Issue;1/ (2020-2021)

\title{
PURPOSE RULES AND THEIR ROLE IN DETERMINING THE REGULATIONS OF DEMONSTRATIONS
}

Teacher assistant Doctor: Salih Muhi Al-Deen Ahmed Abd AlRahman/ Al-Anbar Education Directorate / Fallujah Department/ Sa89moh@gmail.com/ 07516601917

Abstract: Before going into my research, it is necessary to clarify the principles and pillars that I adopt in my research, and the desired goal that is within my research just to study a phenomenon spread in many Islamic countries, which is to break the legislative authority in mass demonstrations. The aim of which is to obtain the rights of the people that the authorities have kept them aside. It was limited in providing them to citizens, so the pillars of these demonstrations were built on regulations set by Islamic Sharia by relying on the principles of purposes that defined these regulations.

My study curriculum was based on the inductive analytical approach, since I relied on extrapolating the intentional rules that affect the arranging of demonstrations, and then I set regulations for the demonstrations based on these intentional rules, and analyze the parts of the regulations to reach at the specific results that serve the community and preserve the lives and property of people.

In conclusion, I recommend that researchers pay attention to study the intended aspects of this subject, since preserving the purposes of legitimacy

071

Doi:10.37940/RJIS 2021.1.15 
Published by the College of Islamic Sciences at the University of Fallujah ISSN p.p:2708-3993 / ISSN o.l: 2708-4000 Vol;1- Issue; 1/ (2020-2021)

has a great role in creating a safe and disciplined atmosphere for the safety of societies.

Keywords: (demonstrations, determining, purpose, regulations, rules) 


\title{
القواعد المقاصدية ودورها في تحديد ضوابط المظاهرات
}

\author{
د. صالح محي الدين أحمد عبد الرحمن/ مدرس في مديرية تربية الأنبار/ قسم الفلوجة/ \\ .v0174.191V/Sa89moh@gmail.com
}

الملتخص:

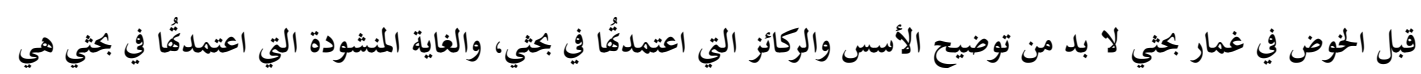

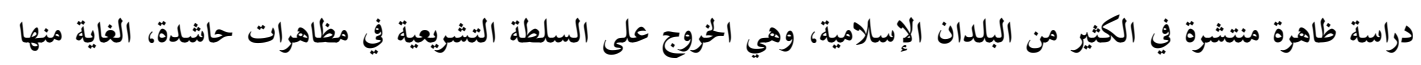

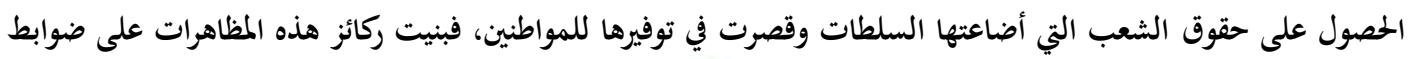

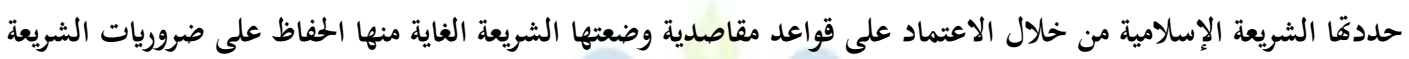
والتي بدورها حددتُ هذه الضوابط.

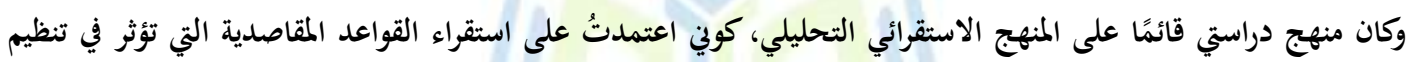

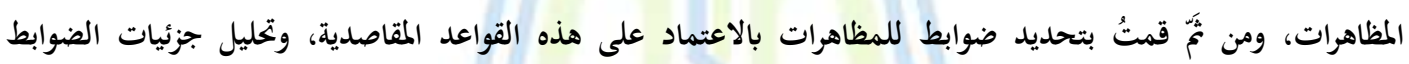

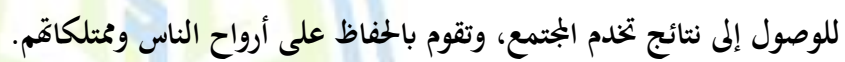

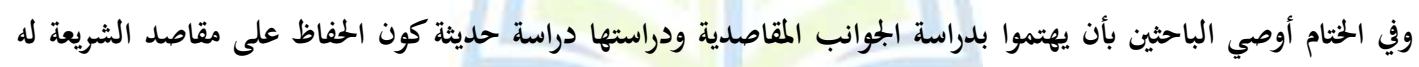
دور كبير في خلق جو آمن ومنضبط لسلامة الجتمعات. الكلمات المفتاحية: (القواعد، المقاصدية، تحديد، ضوابط، المظاهوات)• 


\title{
القواعد المقاصدية ودورها في تحديد ضوابط المظاهرات
}

\author{
د. مالح محي الدين أحمد عبد الرحمن

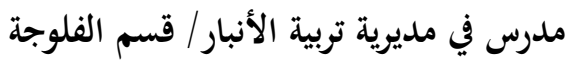

المقدمة

الحمد لله رب العلمين والصلاة والسلام على رسول الله وعلى آله وصحبة أجمعين. أمّا بعد

فلا يخفى على أحد أنّ العمل بالشريعة الإسلامية من أعظم الأعمال وخدمة الدين من أفضل ما يفعله المسلمون في

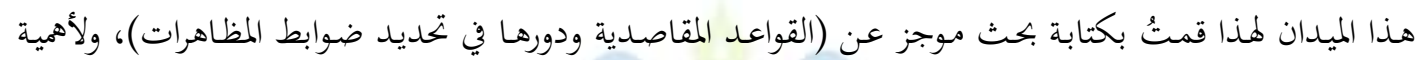

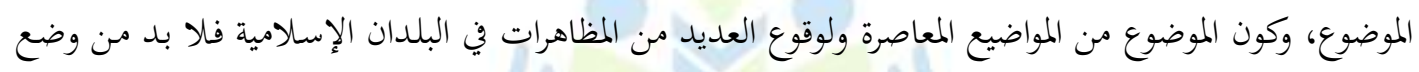
ضوابط لما، حسب القواعد المقاصدية التي تنظم هذه الضوابط ولا تخرجه من المنظور الشرعي. وكان منهجي في كتابة البحث هو المنهج الإستقرائي إذ قمت بجمع القواعد المؤثرة في تحديد ضوابط المظاهرات ثم نظمتُ هذه الضوابط ضمن دائرة القواعد المقاصدية. وكان تقسيمي للعمل إلى ثلاثة مباحث مسبوقة بمقدمة متواضعة: فالمبحث الأول: التعريف بمفردات العنوان، وفيه مطلبان: المطلب الأول: بيان مفهوم القواعد المقاصدية المطلب الثاني: بيان مفهوم الضابط والمظاهرات المبحث الثاني: القواعد المقاصدية في تحديد ضوابط المظاهرات، وفيه ثلاثة مطالب: المطلب الأول: أقسام مقاصد الشريعة. المطلب الثاني: أحوال حفظ مقاصد الشريعة. المطلب الثالث: القواعد المقاصدية في تحديد ضوابط المظاهرات.

$07 \varepsilon$ 
Published by the College of Islamic Sciences at the University of Fallujah ISSN p.p:2708-3993 / ISSN 0.l: 2708-4000 Vol;1- Issue; 1/ (2020-2021)

المبحث الثالث: ضوابط المظاهرات. ثم أذكر قائمة للمصادر والمراجع التي اعتمدثُّا.

والله أسأل أنْ أكون قد وفقتُ لإتمام هذا البحث بالشكل المطلوب، وصلى الله وسلم على سيدنا مُحَّمَ وعلى آله وصحبٍِ أجمين الباحث 


\section{المبحث الأول: التعريف بمفردات العنوان}

بيان كل شيء يتوقف على بيان مفهومه، فقبل الخوض في غمار القواعد المقاصدية، وضوابط المظاهرات لا بد من بيان تعريفات هذه المصطلحات، وسأقسم هذا المبحث إلى مطلبين. المطلب الأول: بيان مفهوم القواعد المقاصدية

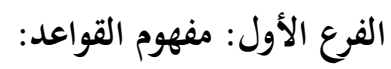
أ- أ - القواعد في اللغة.

القواعد جمع قاعدة، وقاعدة الشيء أساسه وأصوله، ومنه قاعدة البيت أساسُه، وأصول حيطانه(') وقد جاء في

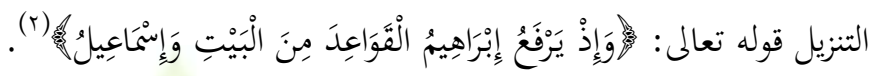

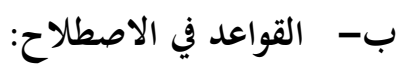
وهي حكم كلي تندرج تحتها أجزاء كثيرة في أبواب مختلفة تنطبق أحكامها على جميع أجزائها(؟). الفرع الثاني: مفهوم المقاصد الشرعية: قبل الخوض في تعريفات علم مقاصد الشريعة باعتبارها لقباً على علم مخصوص لابد من ذكر معنى مقاصد الشريعة

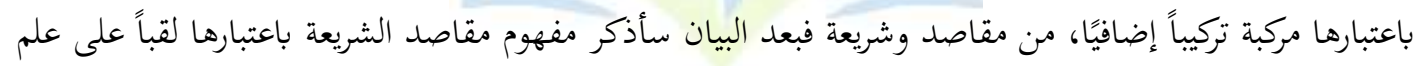
مقاصد الشريعة.

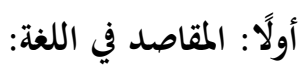
المقاصد جمع مقصد، وأصله من الفعل الثلاثي قَصَََ، والقصد بمادته يدل معنى الإرادة، كقولنا: فلان قصد هذا

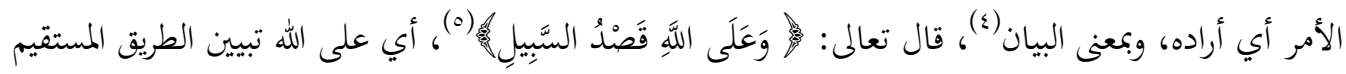

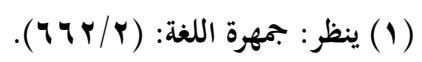

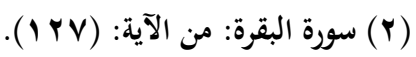

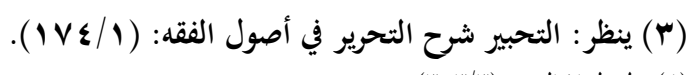

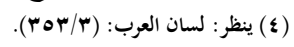

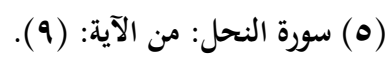
077 
الشريعة: من الفعل شرع يشرعُ شروعاً، والشروع هو الورود، تقول: شرعت الدواب في الماء أي دخلت، والشرع هو الظهور كقولنا: شرعت الشيء إذا أظهرته وأخرجته (1). ثالثًا: الشريعة في الاصطلاح:

ذكر الباحثون والمؤلفون جملة من التعريفات للشريعة منها: "أٔنا ما سنّه الله لعباده من الأحكام عن طريق نبي من

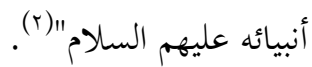

$$
\text { وعرفه الريسوني بقوله: "جملة الأحكام العملية التي تضمّنها الإسلام"(؟). }
$$

رابعًا: تعريف مقاصد الشريعة:

أما معنى مقاصد الشريعة باعتبارها لقبًا لعلم خخصوص فقد عرفه ابن عاشور بقوله: "هي المعاني والحكم الملحوظة للشارع في جميع أحوال الشريعة أو معظمها" (ء). وعرفه الريسوني بقوله: "الغايات التي وضعت الشريعة لأجل تحقيقها لمصلحة العباد"(ه).

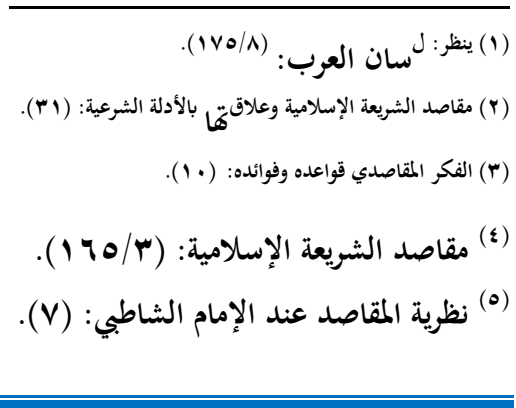


المطلب الثاني: بيان مفهوم الضابط والمظاهرات.

الفرع الأول: مفهوم الضابط: - مفاب

أ: الضابط في اللغة:

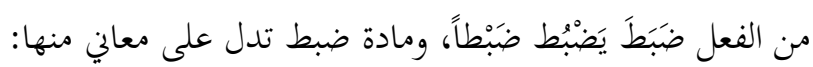

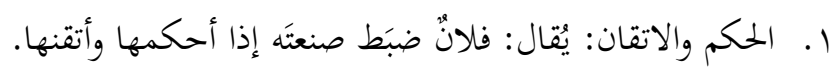

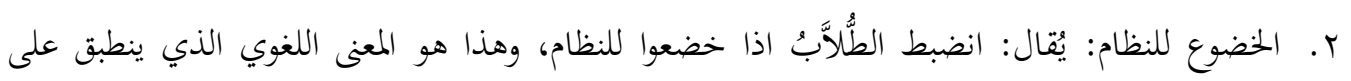

$$
\text { ب: الضابط في الاصطلاح: الضابط المراد هنا(1). }
$$

ذكر الأصوليون لمفهوم الضابط تعريفًا جامعًا مانغًا فعرفوه بقولم: هو كل ما اختص ببابٍ واحدٍ في الغالب، وقصد به جمع صور متشاهةة).

فالعلاقة بين المعنى اللغوي والاصطلاحي هو أنَّ كلا المعنيين يدلان على خضوع أجزاء متفرقة لنظام معين يحكمه.

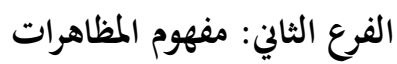

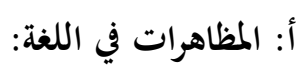
للمظاهرات مفاهيم عديدة منها:

ا. ـ المعاونة والمساعدة والنصرة: أي أنَّ بعض الناس يعاونون بعضهم الأخر، ويتقوى بعضهم ببعض، يُقال: تظاهر القوم على شخص إذا تعاونوا عليه لغلبته ونصرته، وظهرت عليه: أي أعتنه، وظاهر عليه:

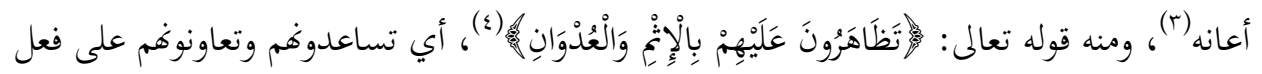

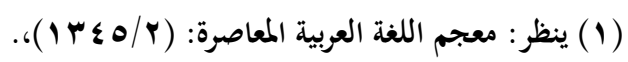

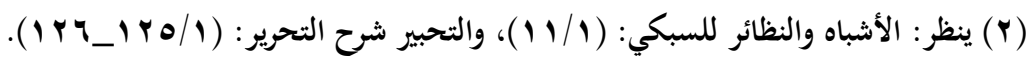

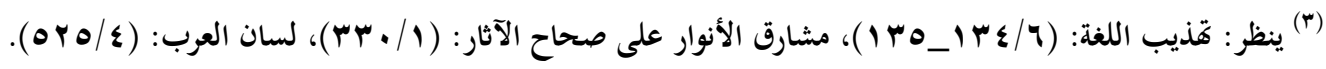

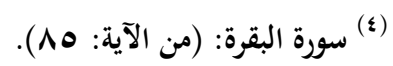

071 
r. المعنى الحديث للمظاهرة: تجمع الناس وخروجهم في الشوارع، تعبيراً عن رأي، أو احتجاجاً على فعل، أو قول، أو مطالبين بأمر يريدونه، ليعلنوا رضاهم، أو سخطهم على أمر يهمّهم، وهذا الذي يسمى

بالمظاهرة، أو المسيرة الشعبية(؟).

$$
\text { ب: المظاهرات في الاصطلاح: }
$$

لم يرد عند الفقهاء القدامى شيء عن المعنى للمظاهرات لأنه لم يكن موجوداً عندهم في وقتهم لكن بسبب تطور

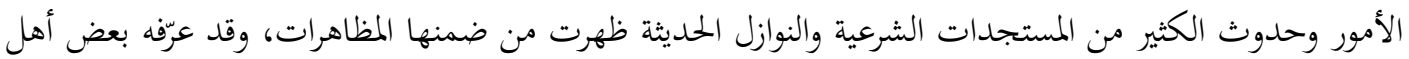

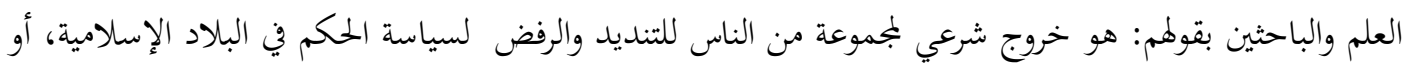

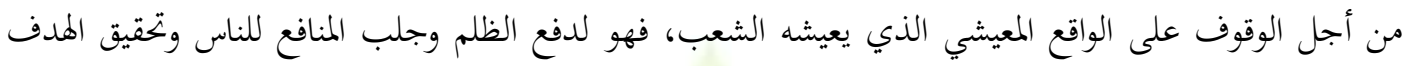
المشترك وفق ضوابط شرعية كفلها الدين (r).

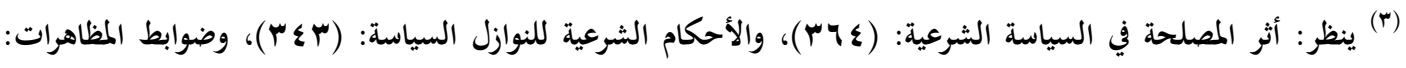




\section{المبحث الثاني: القواعد المقاصدية في تحديد ضوابط المظاهرات}

مقاصد الشريعة جاءت لتحقيق مصالح الناس، من جلب المنافع ودفع المفاسد عنهم، وهذه المصالح تكون واضحة وجلية عندما نظر إليها بمنظور المقاصد الشرعية.

وبميع مفاصل الحياة تدخل ضمن إطار المقاصد، ففي هذا المبحث سأركز على ذكر القواعد المقاصدية

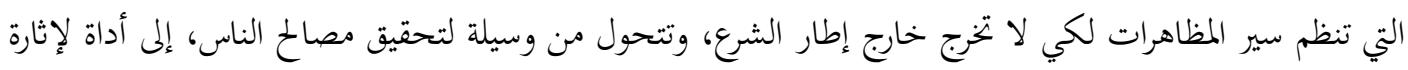

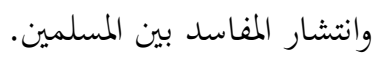

وهذه القواعد عديدة سأتطرق إليها بشكل مختصر، وسأربطها بالضوابط الشرعية للمظاهرات عند ذكري لها كي تكون أكثر وضومًا في المنظور العملي.

وقبل الحوض في غمار هذه القواعد لا بد لِّن من ذكر المقاصد الشرعية بصورة ختصبرة كي تتضح الصورة عند الكلام في القواعد المقاصدية، وكذا في ضوابط المظاهرات.

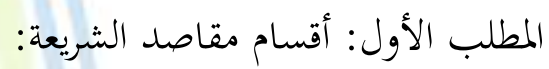

المقاصد الشرعية تنوعت واختلفت وجهات نظر علماء الأصول في تحديد عدد هذه المقاصد، لكن الذي يهمنا في هذا المطلب هو بيان هذه المقاصد بشكل مختصر.

أولاً: حفظ الدين: قوام كل أمة وعزها بجفظ دينها والدفاع عنه، ولهذا اعنتت الشريعة الإسلامية بهذا المقصد كل

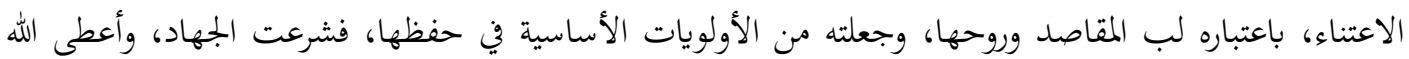

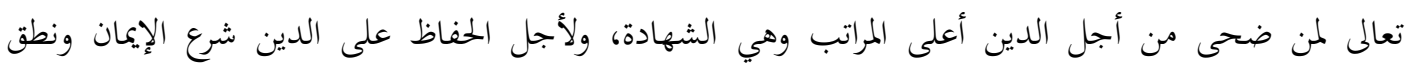

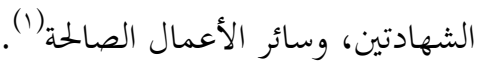

(1) ينظر : مقاصد الشريعة الإسلامية وعلاقتها بالأدلة الشرعية: (01 ().

ov. 
ثانيًا: حفظ النفس: من الكليات الشرعية الثابتة والأساسية هي مراعاة مقصد حفظ النفس، والمراد منه كما ذكرناه

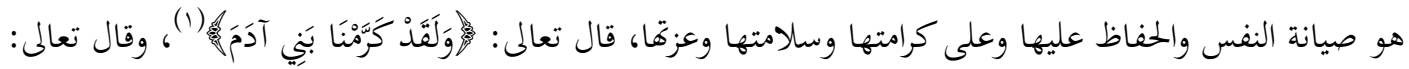

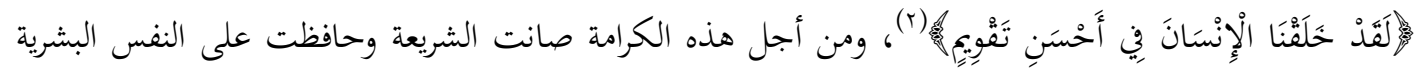

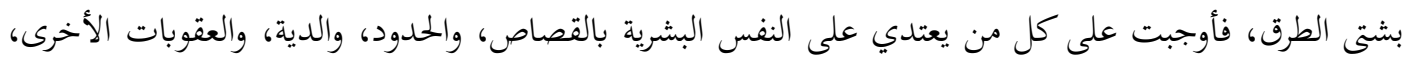

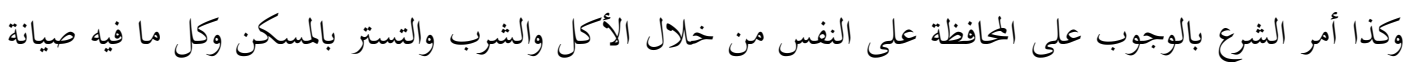
للنفس البشرية(r).

ثالثًا: حفظ العقل: العقل من أعظم المنن التي منَّ الله بها على الإنسان، فهو الذي يميز الإنسان عن البهيمة، وهذا

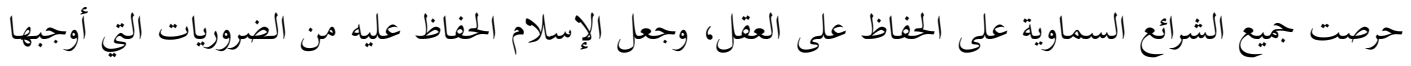

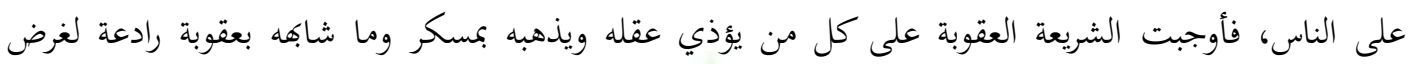

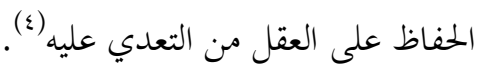

رابعًا: حفظ النسل: سعت الشريعة الإسلامية إلى المحافظة على النسل بشتى الوسائل، فشرعت النكاح للمحافظة

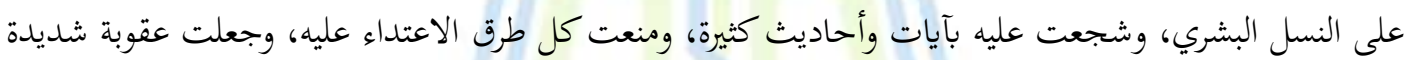

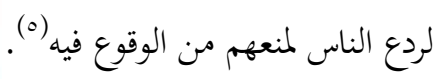

خامسًا: حفظ المال: الأموال قوام الأعمال، وبها حاجات الناس، فنماؤها وحفظها من النقصان والتلف يُعدّ

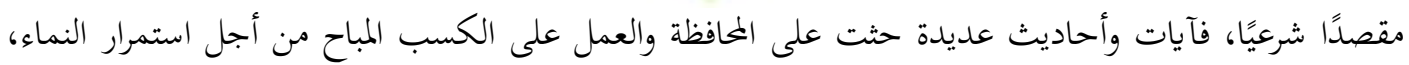
والبُعد عن التبذير وكل ما فيه إتلاف للأموال (؟).

(1) (1) سورة الإسراء: من الآية: (V). (1).

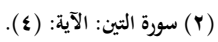
(T) ينظر : علم ال مقاصد الشرعية للخادمي: (1) (1). ( ) ينظر : مقاصد الشريعة الإسلامية وعلاقتها بالأدلة الشرعية: (YYV). (ه) ينظر : المقاصد الثرعية وأثرها في الفقه الإسلامي : (بر ').

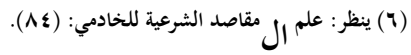




\section{المطلب الثاني: أحوال حفظ مقاصد الشريعة}

للمقاصد الشرعية وسائل وطرق لحفظها، ودفع كل الوسائل التي تؤدي إلى المساس بها والاعتداء عليها، وحفظ هذه المقاصد بأحوال وجوانب مختلقة، وهذا ما سأبينه هنا.

الفرع الأول: حفظ المقاصد من جانب الوجود: والمراد منه إقامة أركان هذه المقاصد، وتثبيت قواعده، بما يحقق

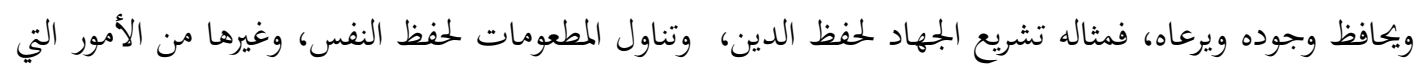
من شأها حفظ مقاصد الشريعة (1).

الفرع الثاني: حفظ المقاصد من جانب العدم المتوقع: والمقصود منه تحذير الناس من المساس بهذه المقاصد عن

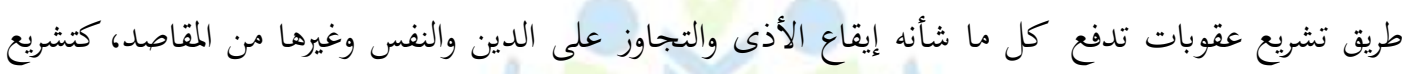

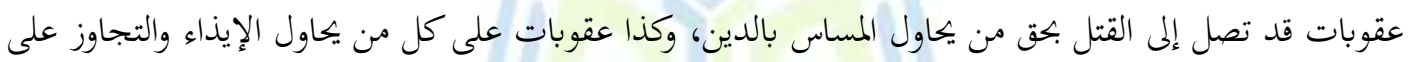

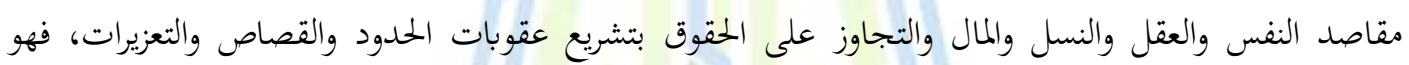
احتراز وقائي مّمّا يتوقع وقوعه وبحاوزه على المقاصد من إخلال (r).

الفرع الثالث: حفظ المقاصد من جانب العدم الواقع: والمقصود منه هو متى وقع اعتداء على أي مقصد من

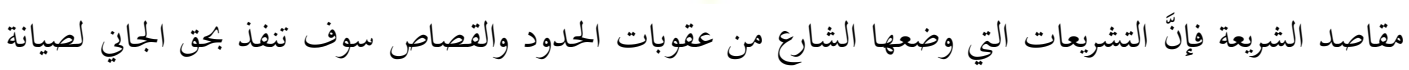

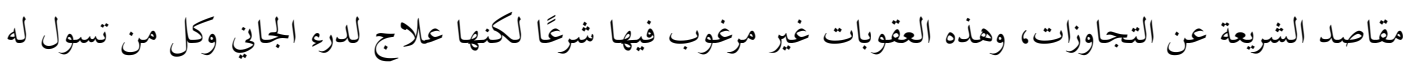

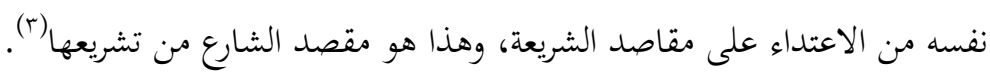

ovr 
إنَّ أنتشار المظاهرات في الأوساط الاجتماعية في مختلف دول العالم يدعو الباحثين إلى النظر في تنظيم وتحديد قواعد

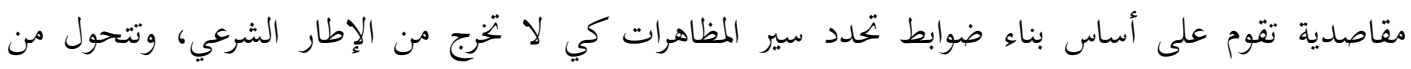

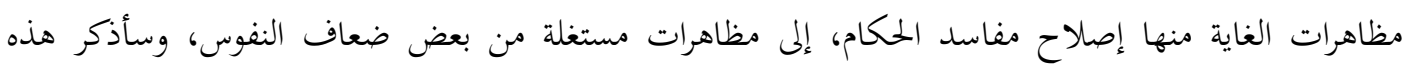

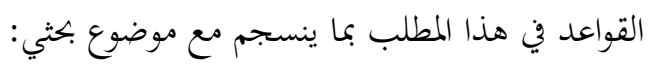
القاعدة الأول: لا ضرر ولا ضرار.

من القواعد الكبرى الخمس التي ينبني عليها الفقه الإسلامي قاعدة (لا ضرر ولا ضرار)، وأصل هذه القاعدة قوله لَّ

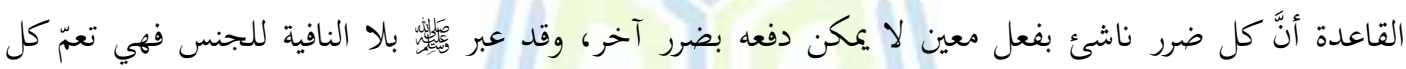
ضرر وهو أبلغ في النهي والزجر (r). وإذا ما طبقنا هذه القاعدة في المظاهرات الشائعة في البلدان المسلمة، فيجب أنْ تكون هذه المظاهرات مظاهرات

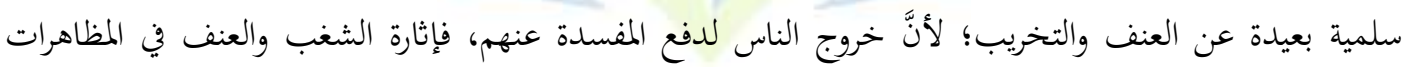

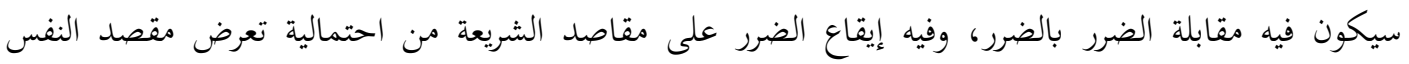
للخطر، كذا المال للتلف والسرقة.

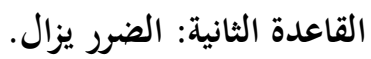
هذه القاعدة تندرج تحت القاعدة الأولى: (لا ضرر ولا ضرار)، والمراد منها هو كل ضرر واقع يجب إزالته

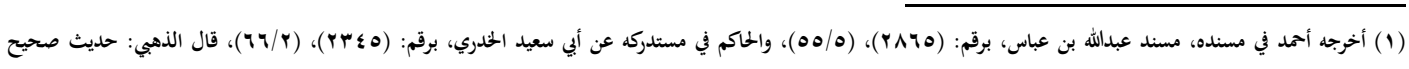

$$
\begin{aligned}
& \text { على شرط مسلم }
\end{aligned}
$$

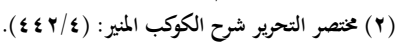

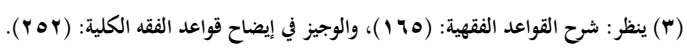

orr 
وخروج الناس بسبب تردي المعيشة أو بسبب سياسة الدولة يجب أن يكون من أجل إزالة الضرر الذي فتك بجسد الشعب، وأرهقه، مع ضمان عدم التعدي على مقاصد الشريعة. القاعدة الثالثة: الضرر الأشد يُزال بالضرر الأخف (†).

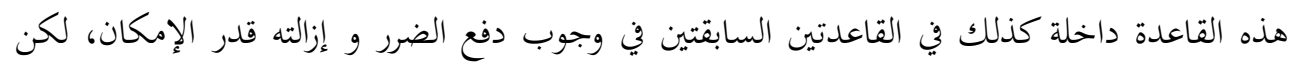

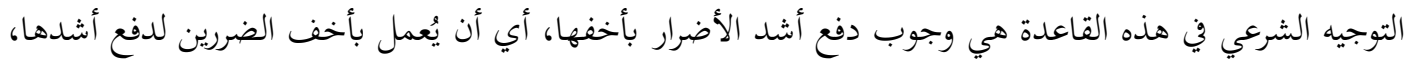

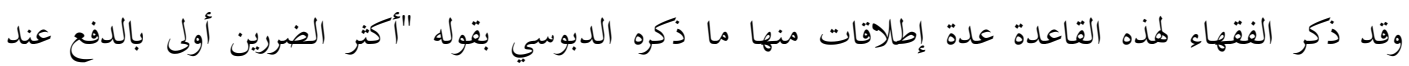

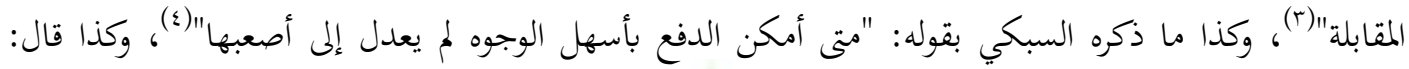

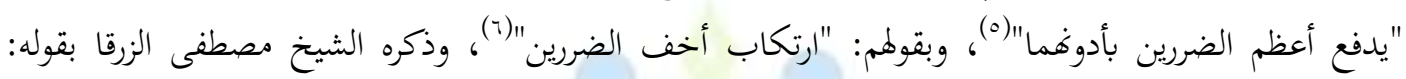

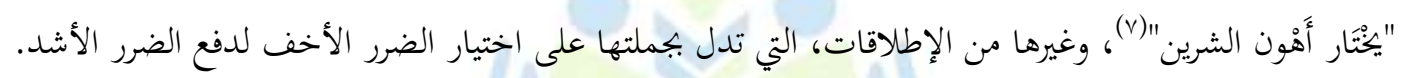
فالمظاهرات الجماهرية التي تشهدها دول العالم لها سُبل عدة، فلا يصح التعبير برفض سياسة دولة بطريقة

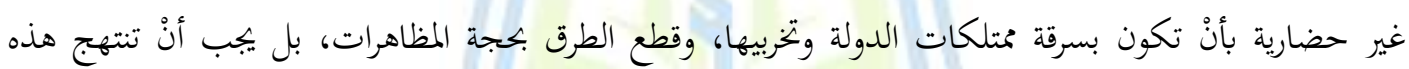

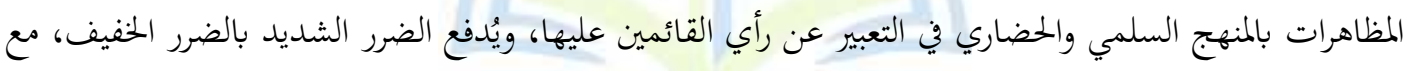
مراعاة ترتيب مقاصد الشريعة في الحفاظ عليها.

(1) ينظر : الأشباه والنظائر للسبكي: (1// ع )، والأشباه والنظائر للسيوطي: (؟)). ( ( ) شرح القواعد الفقهية: (199) ( ).

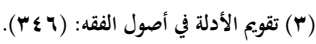
( ) الأشباه والنظائر للسبكي: (1// ؟ ). 
اهتمت الشريعة الإسلامية بمقاصد الشريعة اهتمامًا كبيرًا حتى إنَّا جعلت مراعاة هذه المقاصد في أغلب

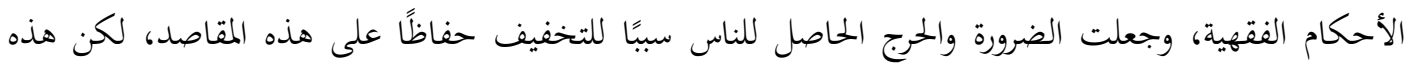

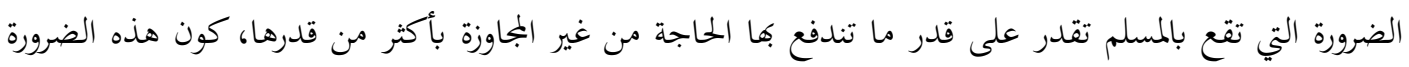
تحول الحكم الشرعي إلى حكم شرعي ثانٍ الغاية منها الحفاظ على مقصد شرعي معتبر (1).

فالمظاهرات مثلاً لو كانت الغاية منها حاجات شخصية، أو أن الجهات التي خرجت عليها المظاهرات قد نفذت

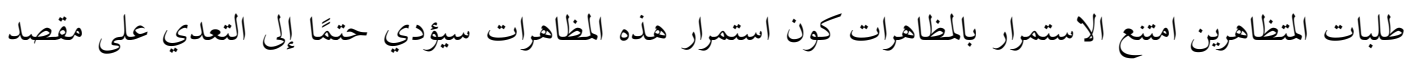

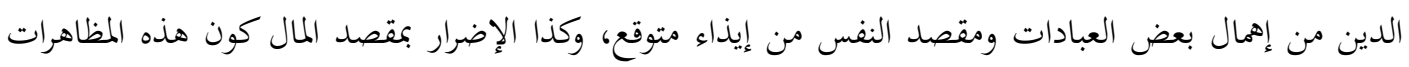

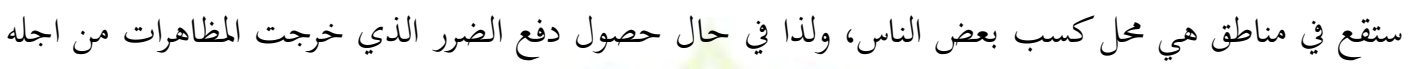
تجب إنهاء هذه المظاهرات لأنَّ الضرورة تقدر بقدرها.

وإنْ لم تنفذ الحكومة طلبات المتظاهرين، فالاستمرار بالمظاهرات حقُ مشروع لحياة كريمة حتى تحقيق أهداف المظاهرة.

\section{القاعدة الخامسة: يتَحَمَّل الضرر الخاص لدفع الضرر العام}

القواعد المقاصدية تنظر دائمًا لما فيه مصلحة العامة، ولا ينبني الأحكام الفقهية من أجل الخاصة، فمن

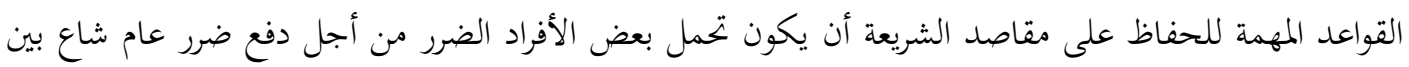
الناس (r)

ولهذه القاعدة المقاصدية أهية كبيرة في تنظيم المظاهرات فقد يتحجج البعض بعدم المشاركة في المظاهرات إذا كان

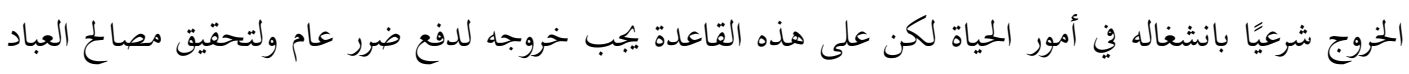

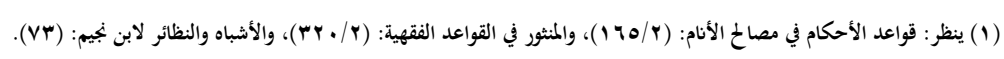

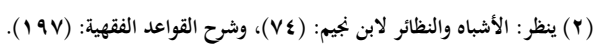

ovo 


\section{Researcher Journal For Islamic Sciences}

Published by the College of Islamic Sciences at the University of Fallujah

ISSN p.p:2708-3993 / ISSN o.l: 2708-4000

Vol;1- Issue;1/ (2020-2021)

ولحفظ مقاصد الشريعة، لقوله له

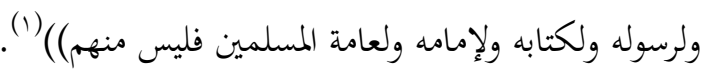

\section{القاعدة السادسة: درء المفاسد مقدم على جلب المصالح.}

نظرتْ الشريعة الإسلامية إلى جميع الأفعال الصادرة من المكلفين إلى المصالح والمفاسد الناتجة عنها، فلو حصل

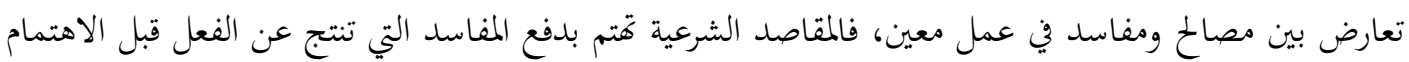

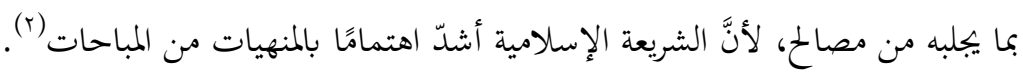

فبعض المظاهرات التي تنتج عنها إشاعة المفاسد من التعدي على مقاصد الشريعة بأنْ يجصل فيه تعلٍ على مقصد

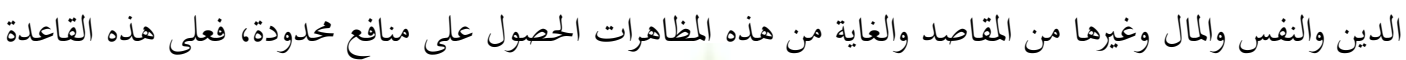

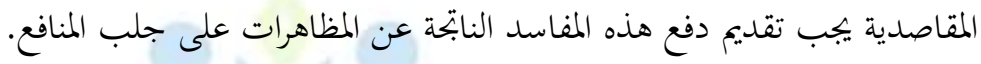

\section{المبحث الثالث: ضوابط المظاهرات}

لم تترك الشريعة الإسلامية أفعال الناس من غير ما تقيده وتضع له ضوابط تُسيره كي لا تكون أفعاهم عشوائية غير

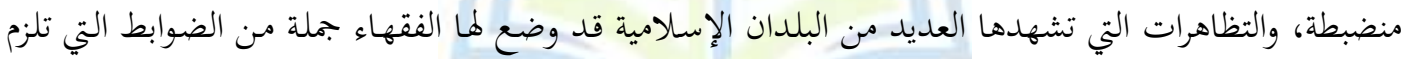

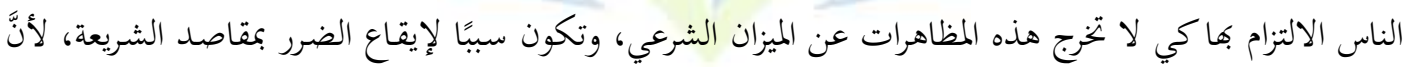

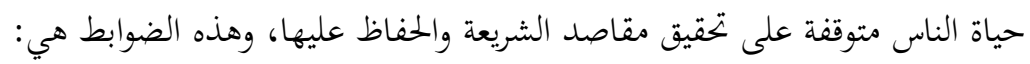

الضابط الأول: أن يكون هناك سبب شرعي للخروج: من أهم الأمور الواجب النظر إليها قبل الخروج على ولي

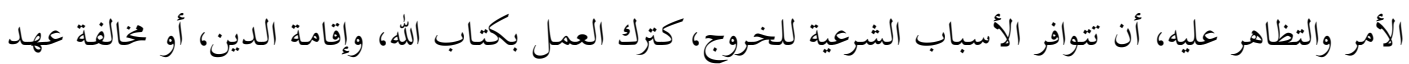

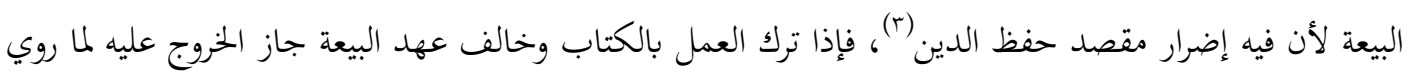

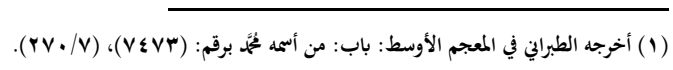

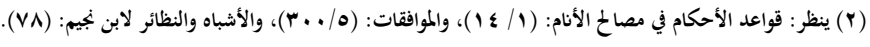

$$
\text { (r) ينظر : الفقه السياسي على منهاج النبوة: (V^). }
$$

OVT 


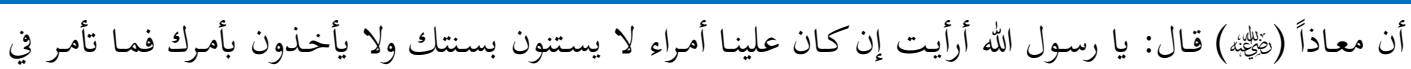

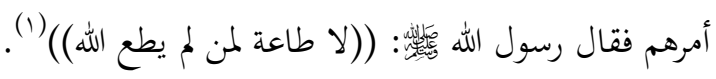

قال القاضي عياض رممه الله تعالى: "فلو طرأ عليه كفر وتغيير للشرع أو بدعة خرج عن حكم الولاية وسقطت

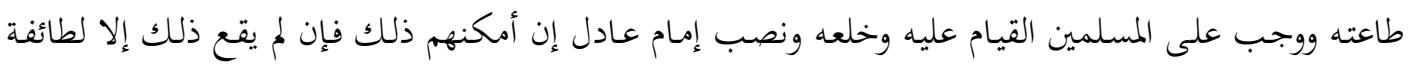

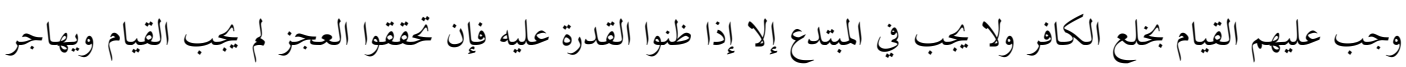
المسلم عن أرضه إلى غيرها ويفر بدينه" (r).

الضابط ثاني: أن تكون الغاية والمقصد الشرعي مطلوباً شرعاً: فإنَّ الشرع الحنيف يتيح ويجيز للناس استخدام كل

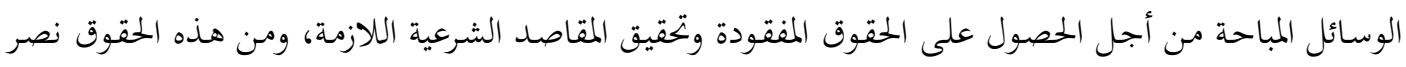

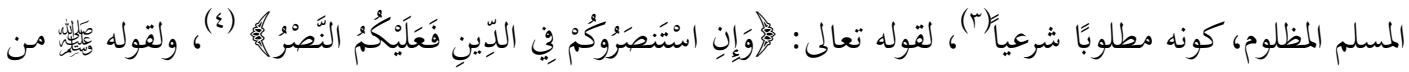

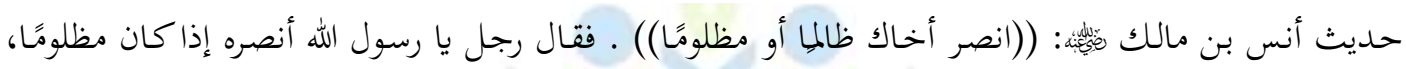

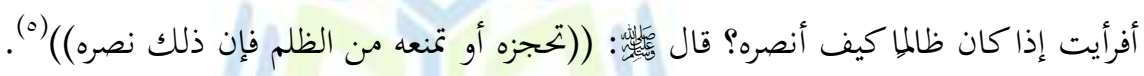

الضـابط الثالث: أن تكون المظاهرات صـادرة عن ولايـة شـرعية: مـ الضوابط الواجب مراعاتـا قبل الخروج

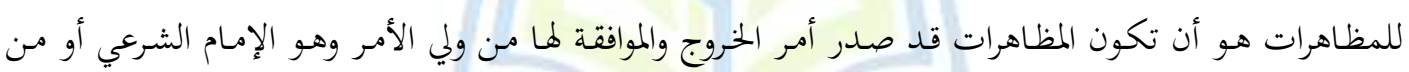

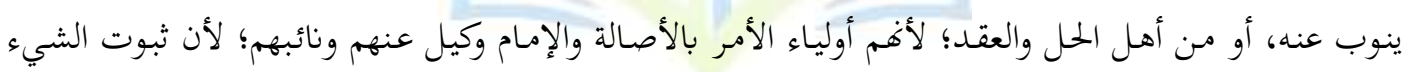

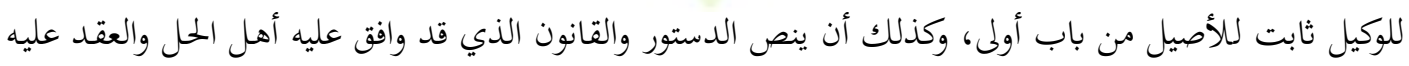

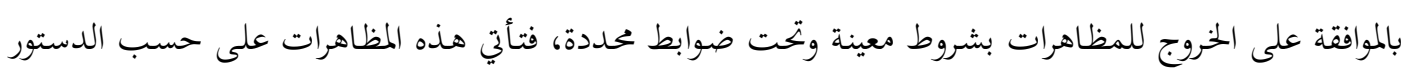

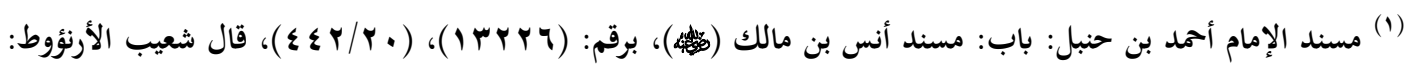

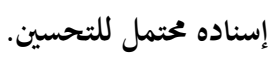

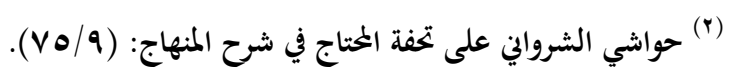

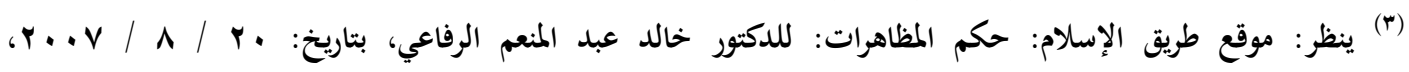
.https://2u.pw/yflcx

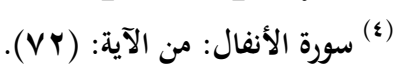

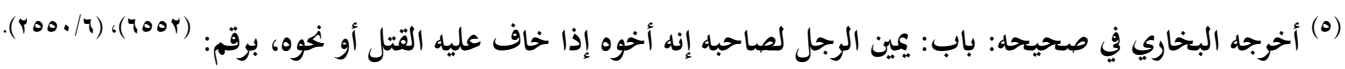
OVY 
والقانون فلا يكون في هذا الخروج أي مخالفة للدستور المقرر، ويتحصل في الالتزام بهذا الضابط صون مقصد الدين

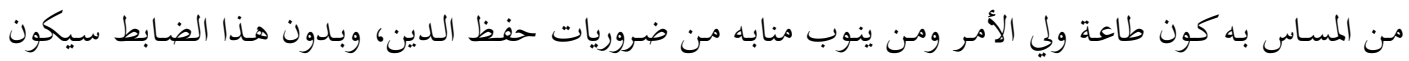
خروج الناس عشوائيًا فيخرج كل من سولت له نفسه ويحرك الناس معه فينعدم الأمن والاستقرار في البلاد (1). أمّا لو كان الإمام أو ولي الأمر هو المعني بالمظاهرات، بأنْ كان ظالميا لشعبه وسلب حقوقهم واعتدى عليهم ففي

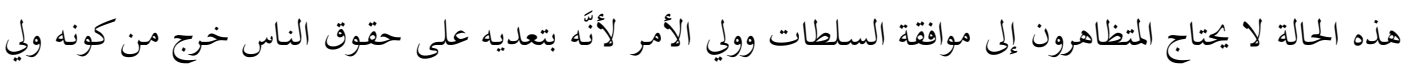

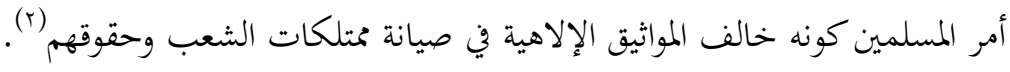

الضابط الرابع: أن تكون المظاهرات مبنية على قاعدة الدعوة إلى الإصلاح بالحكمة والموعظة والمجادلة بالتي هي أحسن (r) : أي أنْ تكون المظاهرات مبنية على أساس الإصلاح، وتقديم النصح والموعظة الحسنة للحكام الحسام

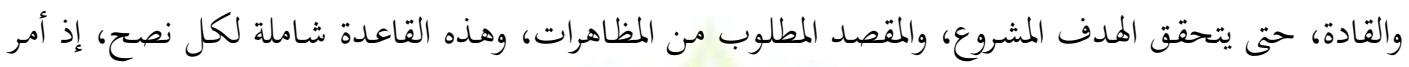

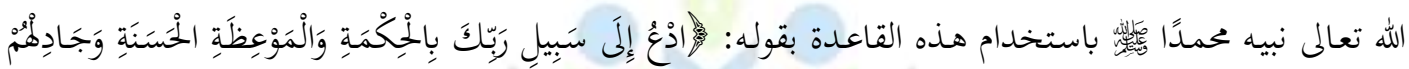

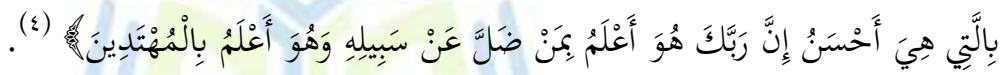
قال القرطبي: "هذه الآية نزلت بمكة في وقت الأمر بمهادنة قريش، وأمره أن يدعو إلى دين الله، وشرعه بتلطف ولين

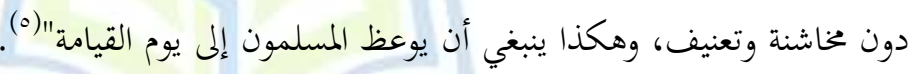
فكما قال القرطبي هكذا ينبغي أن يوعظ المسلمون في كل الأحوال سواء كان الإمام أم الرعية الى قيام الساعة. الضابط الخامس: أن تكون المظاهرات سلمية بعيدة عن العنف وسفك دماء الناس: من أهم الأمور الواجب

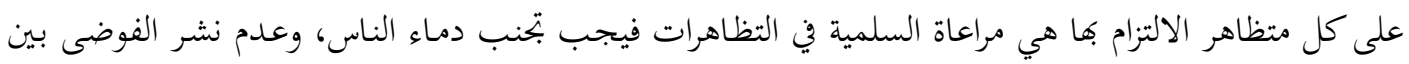

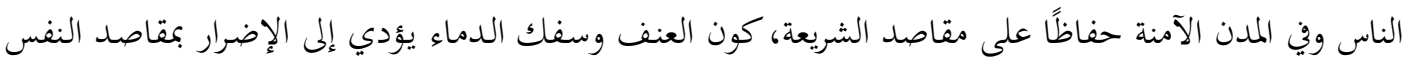

(1) - (1) ينظر : الأحكام الشرعية للنوازل السياسية: (ד؟r).

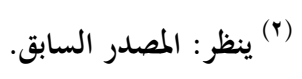

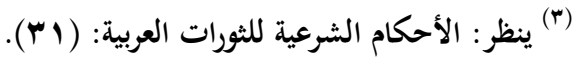

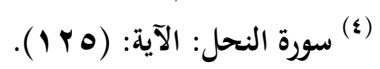

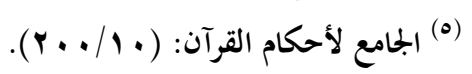

OVA 


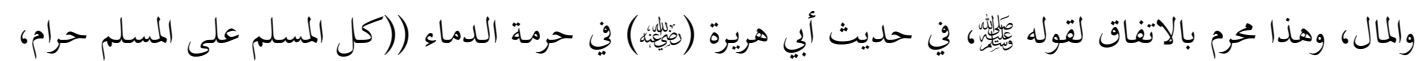

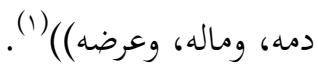

فكما إن الله تعالى أمرنا بالتعاون على البر والتقوى غانا عن التعاون على كل ما يخالف أمره من العدوان على

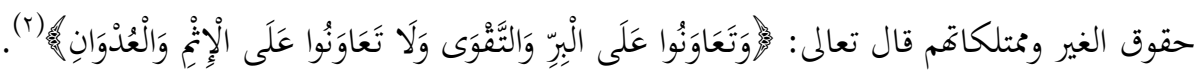

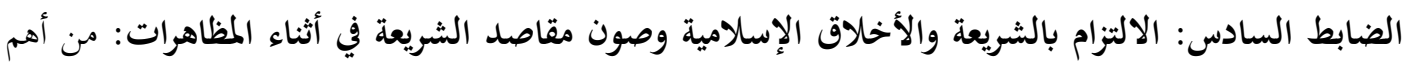

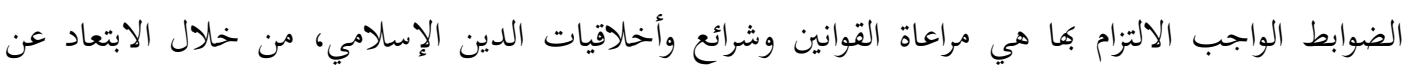

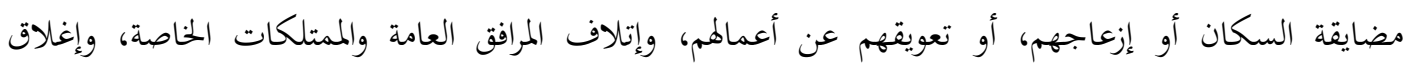

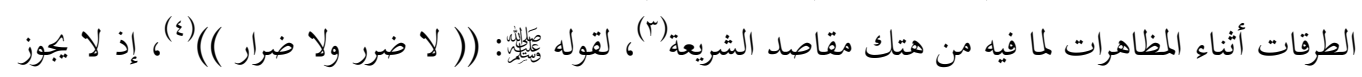
المطالبة بحقوق مع إيقاع الظلم على الغير، أو إيقاع الضرر على الناء الناس.

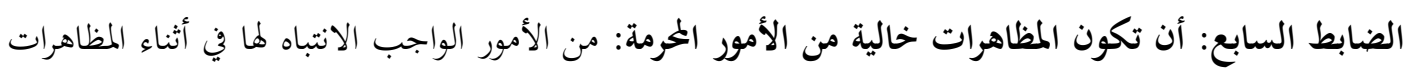

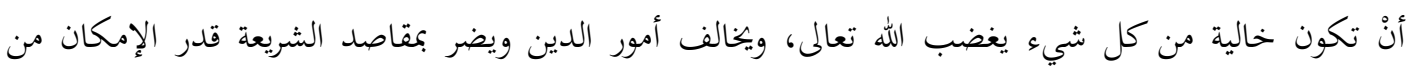

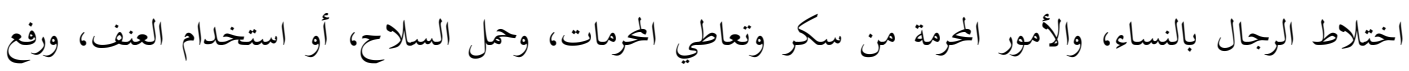

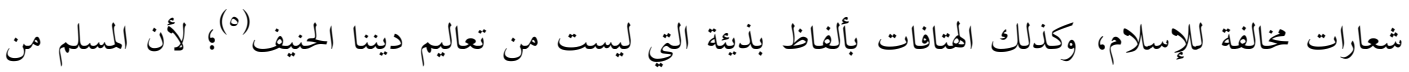

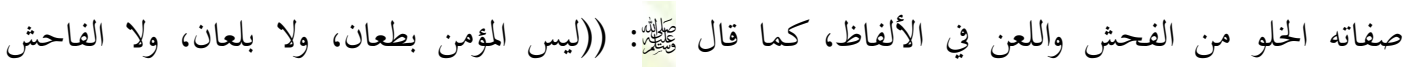

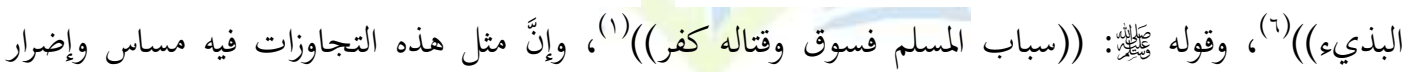
بمقاصد الشريعة، والله تعالى أمرنا بصون هذه المقاصد وعدم التجاوز عليها لأي سبب كان.

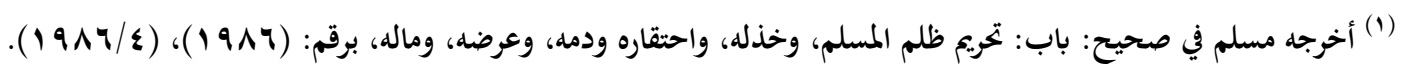

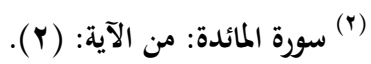

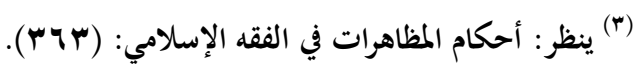

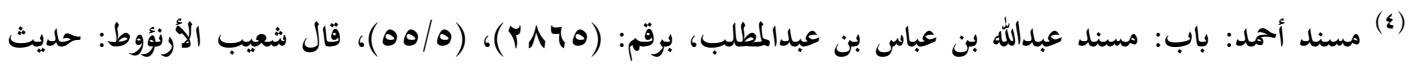

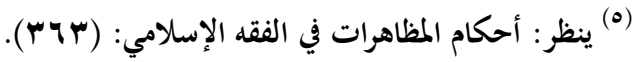

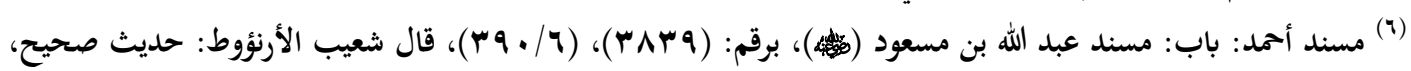
ولكن هذا الإسناد منكر. ov9 
الضابط الثامن: أنْ تحقق المظاهرات المقصد المطلوب منها ولو بغلبة الظن: بأن تؤدي المظاهرات من إضعاف

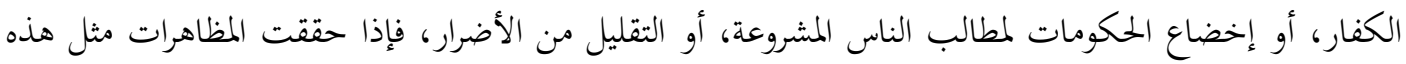

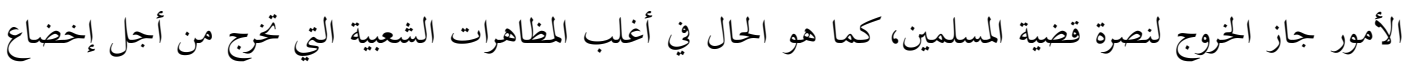

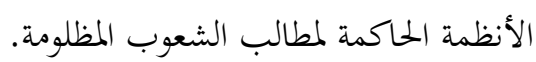

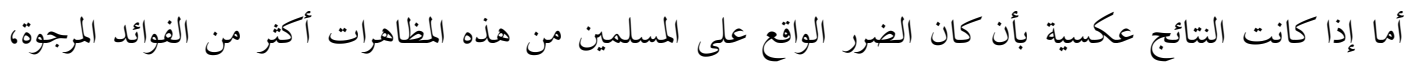

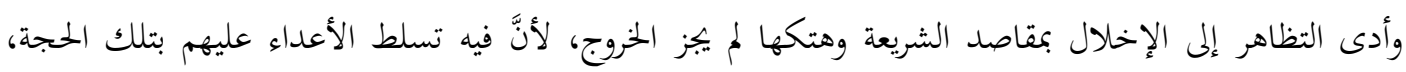

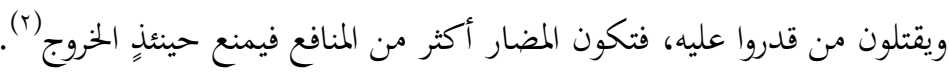
الضابط التاسع: أن تكون المظاهرات جماعية: من الأمور الواجب النظر فيها قبل المشاركة في المظاهرات أنْ تكون

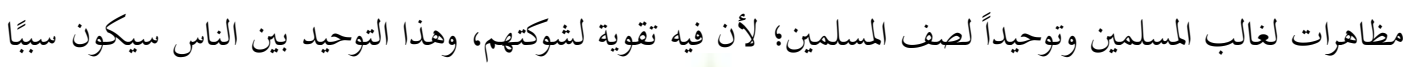

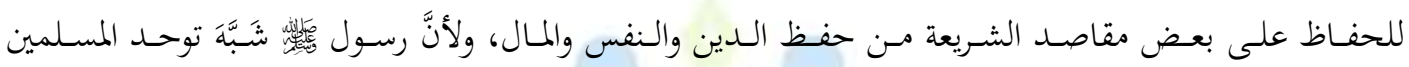

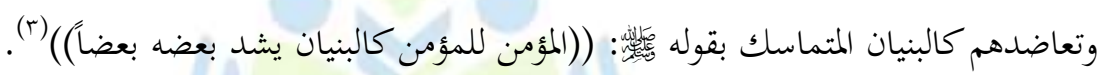
وقوله بالسهر والحمى () (q) (u)

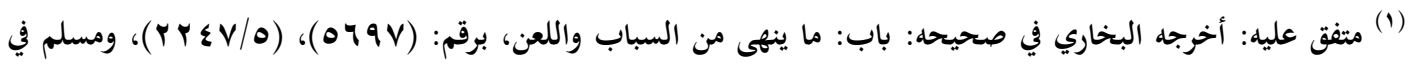

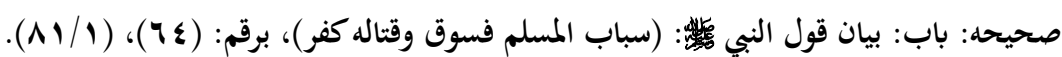

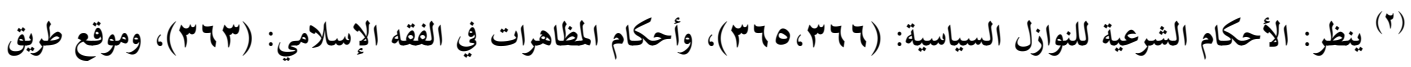

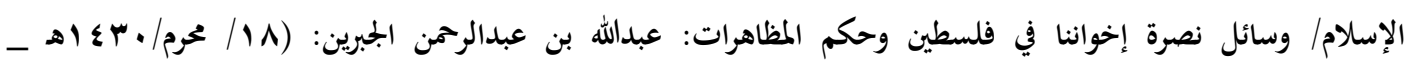

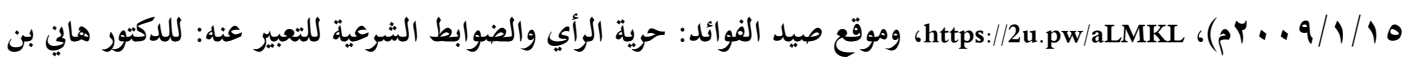
عبد الله بن جبير، وبر

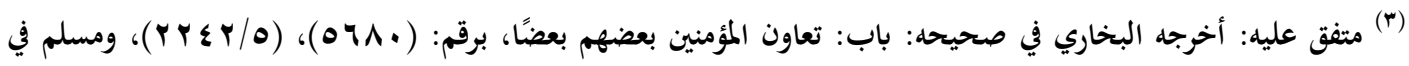

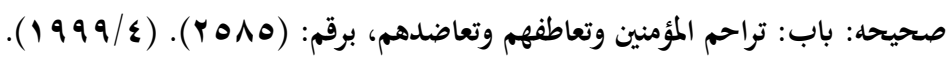

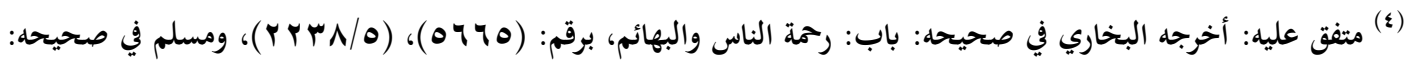

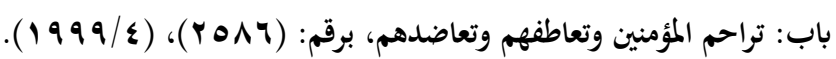
Oᄉ. 
قال الشيخ مُحَّة فؤاد عبد الباقي في شرحه لهذا الحديث: "هذه الأحاديث صريحة في تعظيم حقوق المسلمين بعضهم على بعض، وحثهم على التراحم والملاطفة والتعاضد في غير إثم ولا مكروه" (1).

الضابط العاشر: في حال خروج النساء في المظاهرات يجب الالتزام بالواجبات الشرعية: ذكر بعض الفقهاء بأنه

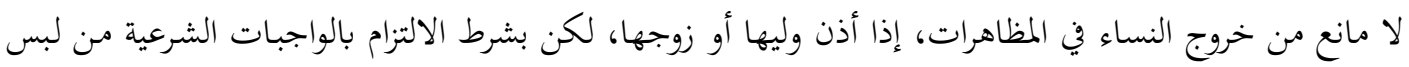

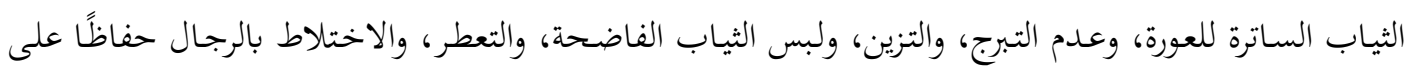

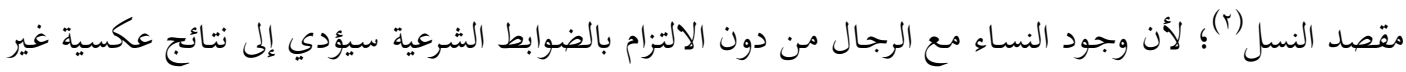

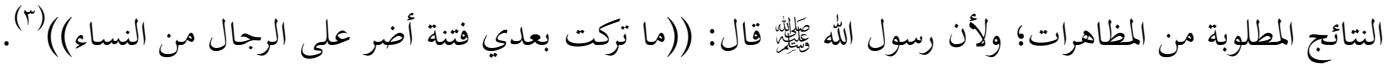
الضـابط الحسادي عشر : ألَّأ تأتي هـذه الوسيلة إلا بعد استنفاذ كـل وسائل الإصلاح: أي أنه لا يتم الخروج

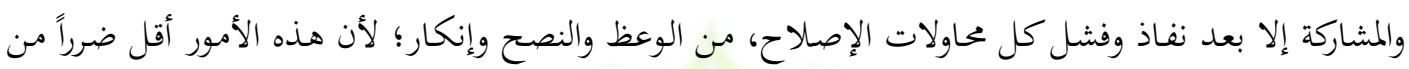

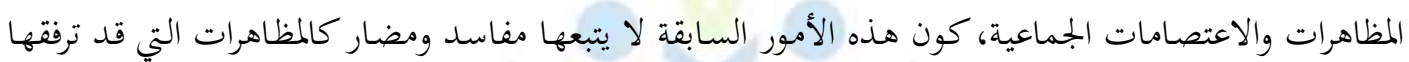
أعمال تتؤدي إلى المفاسد وإيقاع الضرر بالمشاركين.

ولا يصح تقديم وسائل الإصلاح التي قد ترفقها مضار ومفاسد كالمظاهرات على وسائل أخرى لا ترفقها مثل هذه

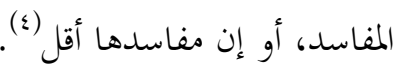
كون الشريعة الإسلامية تدعو دائمًا إلى تحقيق الحفاظ على مقاصد الشريعة بكل الوسائل الممكنة لكن يُقدم الأسهل ولا يتحول إلى الأصعب إلّا بعد نفاذ كل الوسائل الأخرى.

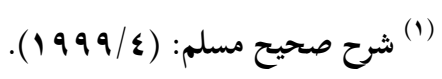

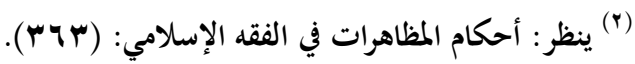

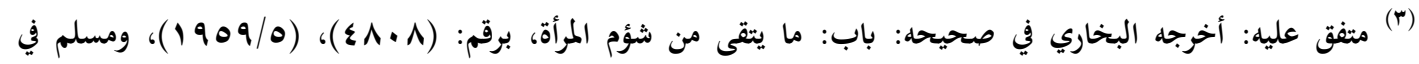

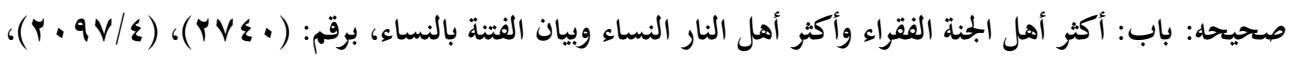

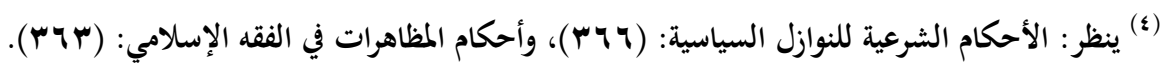
$0 \wedge 1$ 
الحمد لله والصلاة والسلام على رسول الله وعلى آله وصحبه أجمعين. أمّا بعد توصلت في بحثي إلى نتائج أوجزها بما يلي:

ا. إنَّ الخلاف الحاصل بين الفقهاء المعاصرين في موضوع المظاهرات إنما كان بسبب المظاهرات التي لم تلتزم بالقواعد المقاصدية في أثناء خروجها. r. أنْ لا تكون هذه المظاهرات والخروج إليها بطرًا بل لغايات ومقاصد مشروعة.

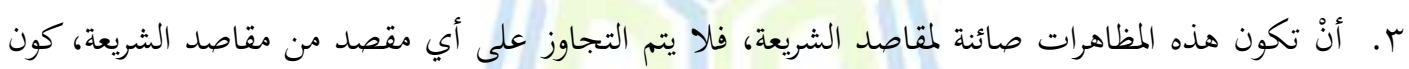
التجاوز على مقاصد الشريعة تنقل حلية المظاهرات إلى الحرمة. ع. أن تكون المظاهرات آخر الحلول أي بعد نفاذ كل وسائل الإصلاح، لما في المظاهرات من تعطيل لحياة الناس.

وفي الحُتام اسأل الله أنْ أكون قد وفقت لإتمام هذا البحث وصلى الله وسلم على سيدنا مُمَّمَ وعلى آله وصحبه وسلم. 


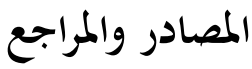

القرآن الكريم.

1. أثر المصلحة في السياسة الشرعية: للدكتور صلاح الدين تُمَّمَ قاسم النعيمي، دار الكتب العلمية - بيروت،

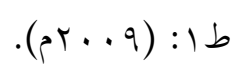

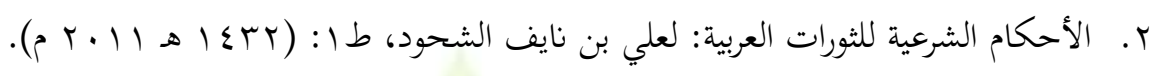

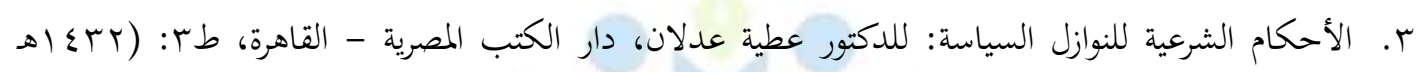

$$
\cdot(5,1)-
$$

ع. أحكام المظاهرات في الفقه الإسلامي: لمروان خلف الضمور، دار المأمون- عمّان، سنة النشر: (. بــ اهـ). ه. الأشباه والنظائر على مذهب أبي حنيفة النعمان: لزين الدين بن إبراهيم بن عُمَّك، المعروف بابن نجيم المصري

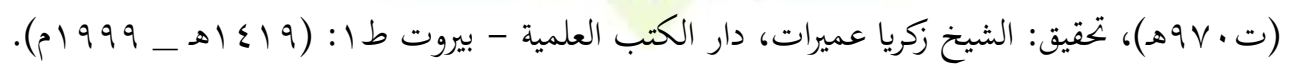

7. الأشباه والنظائر: لعبد الرحمن بن أبي بكر، جلال الدين السيوطي (111)،هـ)، دار الكتب العلمية - بيروت،

$$
\text { ط }
$$

V. الأشباه والنظائر: لتاج الدين عبد الوهاب بن تقي الدين السبكي (ت الهVه)، دار الكتب العلمية - بيروت:

$$
\text { ط) (م) }
$$

^. التحبير شرح التحرير في أصول الفقه: لعلاء الدين أبي الحسن علي بن سليمان المرداوي الدمشقي الصالحي الحنبلي (ته11هـ)، تحقيق: د. عبد الرحمن الجبرين، د. عوض القرني، د. أحمد السراح، مكتبة الرشد -

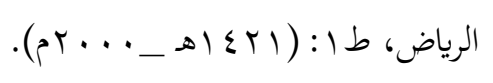

ONH 
9. تقويم الأدلة في أصول الفقه: لأبي زيد عبد الله بن عمر بن عيسى الدّبوسيّ الحنفي (•rعه)، المحقق: خليل

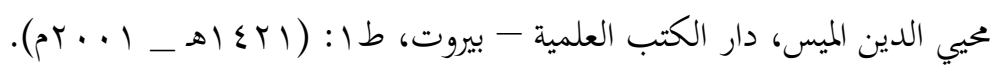

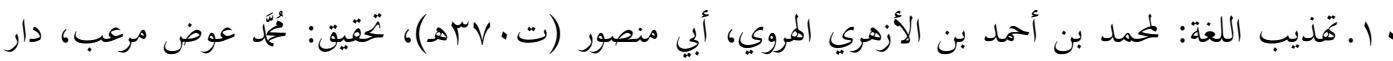

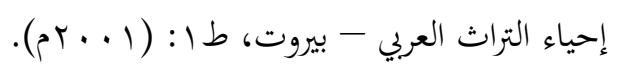

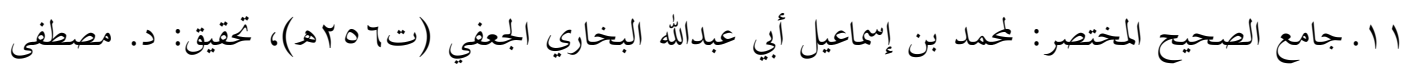

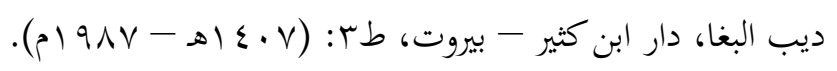

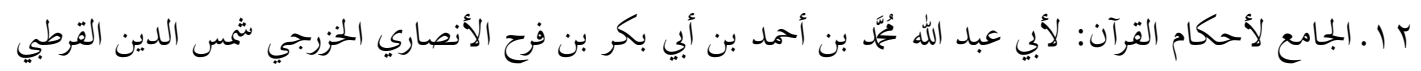

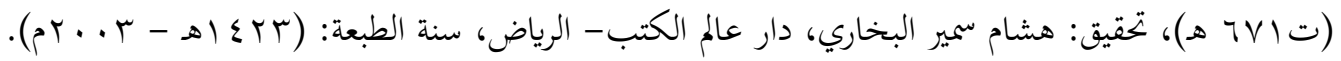

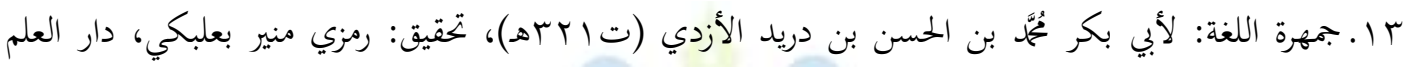

$$
\text { للملايين- بيروت، طا: (91) 19 ام). }
$$

ـ ا. حواشي الشرواني على تحفة المختاج في شرح المنهاج: لعبد الحميد المكي الشرواني (ت ا •باهـ)، المكتبة

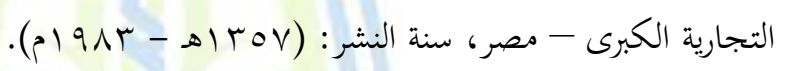

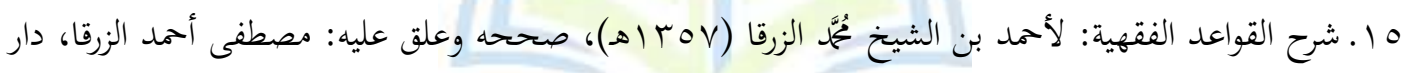

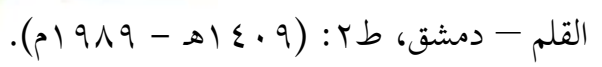

17

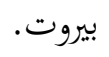

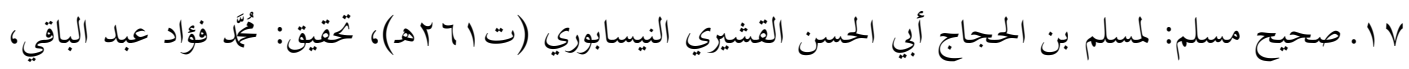

$$
\text { دار إحياء التراث العربي - بيروت. }
$$

11. ضوابط المظاهرات: للدكتور أنس مصطفى حسين أبو عطا، مجلد جامعة دمشق للعلوم الاقتصادية والقانونية -

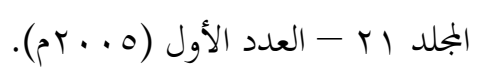

$0 \wedge \varepsilon$ 
9 1. علم المقاصد الشرعية: للدكتور نور الدين بن مختار الخادمي، مكتبة العبيكان - الرياض، طا: (ابكـاهـ -

$$
\cdot(5, \cdot)
$$

•r. الفقه السياسي على منهاج النبوة: لمحمد بن السيد بن حسن بن مُحَّم الخزرجي، دار الكتب العلمية- بيروت،

$$
\text { br. }
$$

ا r. الفكر المقاصدي قواعده وفوائده: لأحمد الريسوني، مطبعة النجاح - الدار البيضاء، سنة النشر: (999 (م). r. بواعد الأحكام في مصالح الأنام: لأبي تُحَّم عز الدين عبد العزيز بن عبد السلام بن أبي القاسم السلمي الدمشقي، الملقب بسلطان العلماء (. ب7هـ)، علق عليه: طه عبد الرؤوف سعد، مكتبة الكليات الأزهرية -

$$
\text { القاهرة، سنة الطبعة: (ع اع اهـ - الم1991م). }
$$

rr. لسان العرب: لخمد بن مكرم بن علي، أبو الفضل، جمال الدين ابن منظور الأنصاري الإفريقى (ت ا الهـ)،

$$
\text { دار صادر - بيروت، طץ (ع اع اهـ). }
$$

ع r. غختصر التحرير شرح الكوكب المنير: لتقي الدين أبي البقاء تُمَّمَ بن أحمد بن عبد العزيز بن علي الفتوحي المعروف بابن النجار الحنبلي (ت وVY هـ)، تحقيق: تُحَّم الزحيلي ونزيه حماد ، مكتبة العبيكان ، طץ:

$$
((199 V+\infty) \leqslant 11)
$$

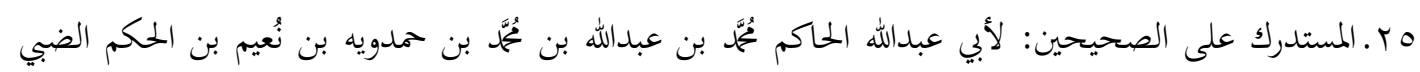
الطهماني النيسابوري المعروف بابن البيع (ه ـ هـ)، تحقيق: مصطفى عبد القادر عطا، دار الكتب العلمية -

$$
\text { بيروت، ط1: (1) (1) إهـ - 199). }
$$




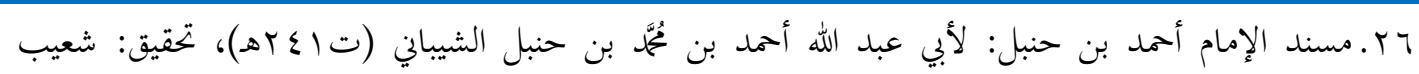

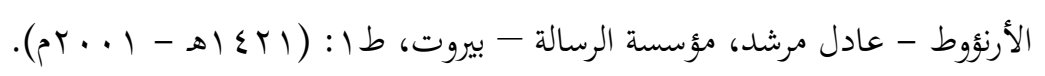

V V.r. مشارق الأنوار على صحاح الآثار: لعياض بن موسى بن عياض اليحصبي السبتي، أبو الفضل (ت ؛ـهـ)،

$$
\text { المكتبة العتيقة - تونس. }
$$

1ץ. المعجم الأوسط: لأبي القاسم سليمان بن أحمد الطبراني (. ب هـه)، تحقيق: طارق بن عوض الله، و عبدالخمسن

$$
\text { بن إبراهيم الحسيني، دار الحرمين - القاهرة، (0 إ اهـ). }
$$

جr. معجم اللغة العربية المعاصرة: د. أحمد مختار عبد الحميد عمر (ت \& ع (هـ)، عالم الكتب - بيروت، طا:

$$
\cdot\left(5 r \cdot r_{-} \rightarrow 1 \leqslant r q\right)
$$

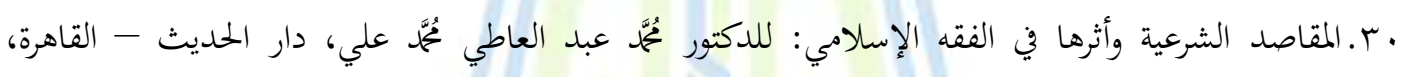

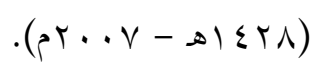

آ. مقاصد الشريعة الإسلامية وعلاقتها بالأدلة الشرعية: لمحمد سعد بن أحمد بن مسعود اليوبي، دار الهجرة -

$$
\text { الرياض، طا: (1) (1) اهـ - (1991) }
$$

rr. الممثور في القواعد الفقهية: لأبي عبد الله بدر الدين تُمَّمَ بن عبد الله بن بهادر الزركشي (ع وهـ)، وزارة

$$
\text { الأوقاف الكويتية - الكويت، طץ: (0. ع اهـ - مد9 ام). }
$$

rr. الموافقات: لإبراهيم بن موسى اللخمي الغرناطي الشهير بالشاطبي (.Vوهـ)، المحقق: أبو عبيدة مشهور، دار

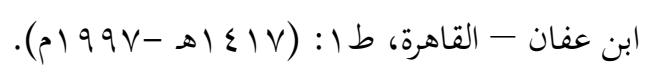

คᄉา 
Published by the College of Islamic Sciences at the University of Fallujah ISSN p.p:2708-3993 / ISSN o.l: 2708-4000 Vol;1- Issue; 1/ (2020-2021)

ع ب.نظرية المقاصد عند الإمام الشاطبي: أحمد الريسوني، الدار العلمية للكتاب الإسلامي - الرياض، طץ:

$$
\cdot(\text { ( } 199 r-\Delta 1 \leqslant 1 r)
$$

هr. الوجيز في إيضاح قواعد الفقه الكلية: للشيخ الدكتور مُحّمّ صدقي بن أحمد بن عُمَّمَ آل بورنو أبي الحارث الغزي،

$$
\text { مؤسسة الرسالة - بيروت، طع: (7 إعاهـ _ 1997)م). }
$$

بr. بوقع صيد الفوائد: http://www.saaid.net/Doat/hani/8.htm.

$$
\text { .https://2u.pw/yflcx موقع طريق الإسلام:.rv }
$$

مبr. موقع طريق الإسلام: https://2u.pw/aLMKL. 